\title{
Music medicine course for medical students in Hungary
}

\author{
Janos Kollar ${ }^{1}$, Pal Kovago², Edit Czegledi ${ }^{1}$
}

'Institute of Behavioural Sciences, Semmelweis University, Budapest, Hungary.

${ }^{2}$ Institute of Cognitive Neuroscience and Psychology, Research Centre for Natural Sciences Hungarian Academy of Sciences, Budapest, Hungary.

Address for correspondence: Janos Kollar,

Institute of Behavioural Sciences, Semmelweis University,

Budapest, Hungary.

janoskollar@gmail.com

Received: February 25, 2016

Accepted: April 24, 2016

Published: ?

\section{ABSTRACT}

Objective: In 2006 a Music Medicine credit course was initiated on Medical and Health Science Centre of University of Debrecen, Hungary for helping the medical students to gain more knowledge about Music Medicine and to dissolve prejudices and misbeliefs about the topic. The aims of the study besides the introduction of the course was thematic quantitative and qualitative analysis of the students' evaluation about the course $(n=150)$. Methods: A short, six-item questionnaire concerning the evaluation of the course was constructed for the purpose of this study. We used both qualitative and quantitative analysis. All of the participants $(n=150)$ in the cross sectional survey were $1^{\text {th }}$ to $6^{\text {th }}$ year medical university students Medical and Health Science Centre of University of Debrecen, (Hungary). Data were collected between the years 2006-2012. Results: Evaluation of the course proved to be especially favourable regarding every measured aspects. The most favourable score showed the evaluation of the teacher and the least one was the individual participation. Content analysis resulted in four content categories, namely group cohesion, self-awareness, practical focus, and new perspective. Conclusions: Besides transferring useful information regarding the possibilities of applying music in medical practice a new as a "side-effect" the course improved the group cohesion between students, and helped them to overcome their shyness, and be more open to their fellow students.

KEY WORDS: Music Medicine; Medical students; Content analysis; Group cohesion; Self-awareness.

\section{INTRODUCTION}

\section{Music medicine and medical training}

Music and medicine has been connected for thousands of years. Although music is used for therapeutic purpose since the ancient era Music Therapy as a profession has been organized only in the last century when the therapeutic effect of Music Therapy in was proven by scientific evidences. Music Therapy is based on medicine, psychoanalysis, humanistic psychology and behaviourism [1]. Kemper and Danhauer [2] drew the attention to the therapeutic effects of music in treatment of anxiety, improving mood for medical and surgical patients, for patients in intensive care units and patients undergoing procedures, and for children as well as adults. The authors pointed out that music is a low-cost intervention that often reduces surgical, procedural, acute, and chronic pain, improving the quality of life for patients receiving palliative care, enhancing a sense of comfort and relaxation, having even indirect effects by modifying caregiver behaviour. Zárate and Diaz [3] underlines that music therapists are trained not only in music theory and performance, but also in psychology, anatomy, research techniques, and other subjects. The authors points out that we can find Music Medicine (music interventions used by medical professionals) research in many areas such as the effects of music in children with autism, adults with psychiatric illnesses, elderly with Alzheimer and Parkinson disease, people with brain injuries, among others.
Taylor [4] gives a broad review of the common history of music and medicine giving special suggestions for improving Music Therapy in medical research and education. Thaut [5] emphasizes that the theory and clinical practice of Music Medicine is changing more and more from a social science model to a neuroscience-guided model based on brain function and music perception thus moving Music Medicine from an adjunct modality to a central treatment modality in rehabilitation and therapy.

Maranto [6] calls the attention to the relevance and importance of university programs designed to focus on rehabilitation or medical applications of Music Therapy creating the basis for practicing Music Medicine. She considers important to include programs into university trainings wherein students would have opportunities to take courses, receive specialized training, and complete practice in these areas. According to her opinion such programs could be interdisciplinary in nature and could also involve students from other disciplines receiving specialized training in Music Medicine.

There are also other initiations [7] aiming at the integration of music into medical schools.

Although the therapeutic effect of music in medical treatments is proven by several medical evidences Music Medicine courses are still missing from the regular curricula of medical universities in Hungary. 


\section{Objective}

In 2006 Music Medicine was introduced into the curriculum of medical students on Medical and Health Science Centre of University of Debrecen. The course was offered for the students as an elective credit course in every semester except in 2008 when the technical and administrational reasons (moving to another building) couldn't make it possible. The course gave the unique opportunity for Hungarian and foreign students to participate in the same group together. The official language of the course was English so the Hungarian students also were speaking in English during the course. One of the "hidden" aims of the course was breaking the communicational barriers between students with various nationalities. The last Music Medicine credit course was organized in 2012. The reason of finishing was that the leader of the course János Kollár, assistant professor has left University of Debrecen and has been continued his work in Budapest at Semmelweis University.

All of the courses were filled up to maximum number of students proving that medical students are interested in the topic and are open for gaining more knowledge about the possibilities of applying music in medical practice.

The practice-oriented and interactive courses consisted of 4 meetings 5 hours per each (altogether 20 hours) and focused on the role of Music Medicine in the practice of medicine. The first part of the meetings was the time of students' presentations and the second part the participants had the opportunity to experience some practical methods of Music Medicine. The first meeting was an exception from this point of view since at the beginning of the course the discussion of the basic rules was followed by the practical part immediately.

The course was aiming at the following goals: a) introducing the basics of how to apply music in supportive therapies in medical treatments, b) making distinctions in between Music Medicine and Music Therapy, c) breaking the cultural and communicational barriers between the Hungarian and foreign students, d) supporting the self-confidence of the participants by involving them into common activities of Music Medicine.

The following text was indicated on the homepage of the University advertising the course: "Aim of the course: Introduction into the knowledge of different types, methods and medical application of Music Medicine. The participants have the opportunity of having their own personal experiences on the field of Music Medicine.

Music Medicine credit course:

\section{Meeting No. 1:}

Definition, history, aim, types and system of Music Therapy

What do music therapists do?

Music Medicine I. (theory, prevention, treatment, rehabilitation)

Personal experiences I.
Meeting No. 2:

Music Medicine II. (Parkinson disease, Alzheimer's disease, organic and intellectual stimulation)

Personal experiences II.

Meeting No. 3:

Music Medicine III. (pain alleviation, improving mood, pre-, peri- and postoperative applications)

Personal experiences III.

Meeting No. 4:

Music Medicine IV. (review of results of the participants' individual research work, verification of the knowledge acquired)

Personal experiences IV."

The "personal experiences" part included some practical methods of Music Medicine:

nonverbal introduction using a piano keyboard and analysing the form of it (icebreaking exercise, helps in "tuning" on the style and topics of the course), introduction by singing own name, discussing the impacts,

painting while listening to music (Mozart: Symphonie Nr. 35 D-Dur KV 385), storytelling inspired by music (Chick Corea: The Mad Hatter),

"conductor game": rhythm improvisation using everyday tools (pencils, plastic bags, books etc.), clapping, human voice and hitting different parts of the body - one of the participants conducts the rest of the group, regularly changing the "conductors", discussing the role of rhythm in life, relaxation to music,

dancing to music: creating own choreography to classical music (Corelli, Torelli, Beethoven) and discussing the emotional reactions, presenting music: introducing the "personal best" piece of music (folk, classical or jazz, maximum 10 minutes long per each) and talking about the reasons of the personal preferences.

\section{METHODS}

All of the participants $(n=150)$ in the cross sectional survey were lth to 6th year medical university students Medical and Health Science Centre of University of Debrecen, (Hungary). Data were collected between the years 20062012. None of the participating students refused the participation in the study nevertheless some of them were missing at the time of filling the questionnaires out $(n=14)$.

At the end of each course the students were invited to complete a paper-and-pencil questionnaire anonymously, which took approximately 5 minutes. They were not remunerated for participation and taking part in the study was voluntary. A short, six-item questionnaire concerning the evaluation of the course was constructed for the purpose of this study: 1) Overall evaluation of the seminars; 2) How the aims of the seminars and the related exercises met my requirements; 3) Individual involvement on the seminars; 
1 4) The involvement of the group on the seminars; 5) The 2 usefulness of the seminars; 6) Evaluation of the seminar 3 teacher. Items were rated on 7-point Likert-type scales (0 $4=$ weak, 6 = excellent), with higher scores reflecting higher 5 satisfaction. After each question, participants were able to 6 evaluate various aspects of the course using their own words, 7 and there was an "extra" item (No. 7) where the students 8 had the opportunity for making notes, observations and 9 suggestions regarding course (see Supplement 1).

Table 1. Descriptive statistics and Spearman's rank correlations among variables

Note: ${ }^{* * *} p<.001$ the requirements" item didn't show significant difference neither from "group activity" nor from "usefulness" and we couldn't find statistically significant difference regarding the means of the latter two items either (Figure 1).

According to the results of Spearman's rank correlation analyses the year of data collection didn't show significant linear association with any of the items of course evaluation. Nevertheless we could find several significant positive and modest correlations between the items of course evaluation. The individual participation was an exemption since it showed significant association only with the general evaluation of the course and with group activity. Descriptive statistics and the correlation among variables are presented in Table 1.

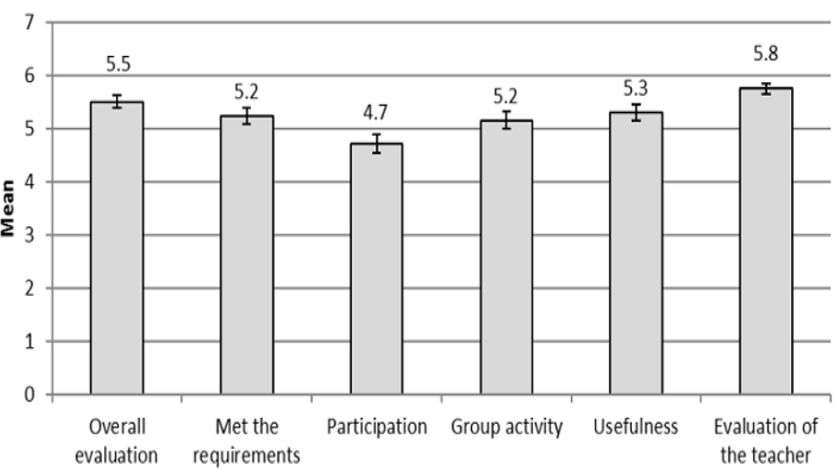

Figure 1. Mean values of evaluation items with their $95 \%$ confidence intervals

\section{Content analysis}

Altogether 404 text replies were processed during the analysis. 340 of them (84.2\%) concerned the questions evaluating six different aspects of the course (mean: 56.7, SD: 4.27 , range: $53-64$ ), and 64 replies (15.8\%) referred to other notes about observations and suggestions regarding the course.

\section{1} 2 3

\begin{tabular}{|c|c|c|c|c|c|c|c|}
\hline Variables & 2 & 3 & 4 & 5 & 6 & 7 & Mean (SD) \\
\hline Year & -0.01 & 0.15 & 0.02 & -0.15 & -0.05 & 0.01 & 2009.9 (1.99) \\
\hline Overall evaluation & & $0.47^{\star \star \star}$ & $0.41^{* * *}$ & $0.47^{* * *}$ & $0.35^{\star * *}$ & $052^{* * *}$ & $5.5(0.72)$ \\
\hline Met the requirements & & & 0.13 & $0.35^{\star \star *}$ & $0.43^{* * *}$ & $0.48^{* * *}$ & $5.2(0.98)$ \\
\hline Participation & & & & $029^{\star * *}$ & 0.09 & 0.12 & $4.7(101)$ \\
\hline Group activity & & & & & $030^{* * *}$ & $0.37^{* \star *}$ & $5.2(0.96)$ \\
\hline Usefulness & & & & & & $045^{\star \star \star}$ & $5.3(0-93)$ \\
\hline Evaluation of the teacher & & & & & & & $5 . S(0-57)$ \\
\hline
\end{tabular}


1 According to the results of the content analysis four 2 content categories emerged referring to specific aspects of 3 the quality and/or evaluation of the course: group cohesion, 4 self-awareness, practical focus and new perspective. 5 These content categories were grouped according either 6 the goals of the course (facilitating group cohesion and 7 intercultural relations), or the evaluation of the course by 8 the participants. Although no explicit question referred to group cohesion, one-third of the participants (36.1\%) reported that the courses helped to increase group cohesion, the courses proved to be a great opportunity to get to know the foreign students and even other Hungarian students. Group cohesion category also contains comments about how much participants learned about teamwork. As one student expressed it: „I was lucky to meet great people at a great time! I wasn't the only one who had a hard time opening up in front of others, but despite it all we truly became a group. I really hope this is just the beginning!"

Nearly a quarter of the participants $(23.3 \%)$ reported that the course served as a valuable experience in getting to know a new field of medicine.

„We saw so many interesting novelties. I think that I can use everything that I've learned in my future practice." "Specific factors during this course has changed in a way how I appreciate music. I will definitely use this experience in coming future."

These new experiences not only included novel knowledge about Music Medicine, but also made the participants more open to alternative approaches to medicine.

More than twenty percent $(22.5 \%)$ of the students underlined the practical focus of the courses as one of the highpoints of the semester. These participants reported that it was refreshing to hear about actual treatments and actual cases, when most of their studies have a mainly theoretical focus.

Last, but not least it seems that the courses served as a selfawareness group as well.

"I got to understand a lot of things about music and myself which I never really bothered about before.",

Over one quarter of the students (25.9\%) shared that during their encounter with Music Medicine they learned how they react in group situations, tried to overcome their shyness, and be more open to their fellow students. Some even added that this "self-awareness" experience is the most important aspect of the course, since it enables for a better overall ability to work with patients and with colleagues.

The mean percentages of the observed content categories are displayed in Figure 2. The relatively low percentages can be explained by the fact that not every participant added additional comments to the Likert-type questions, which could explain the seemingly low percentages despite the high Likert-type evaluations (see above). The large confidence intervals of the percentages might be due to the low sample size and to the regularity of the course.

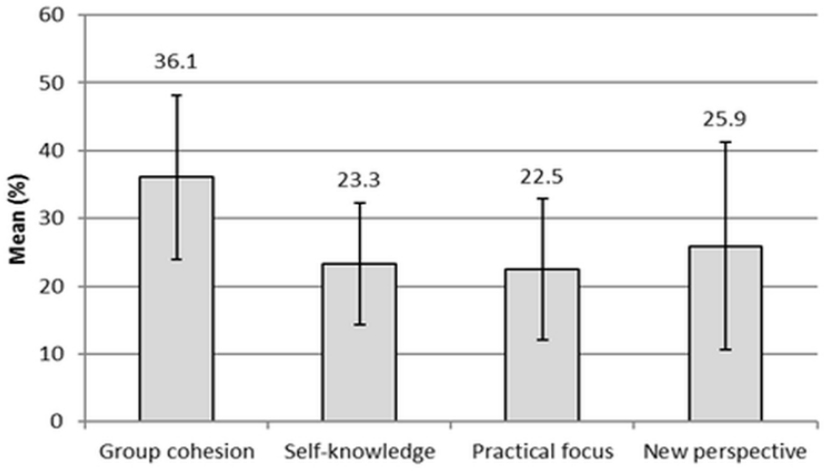

Figure 2. The observed mean percentages of the four main content categories accross all semesters. The figure presents $95 \%$ confidence intervals of the mean percentages.

\section{CONCLUSIONS}

Music Medicine can be regarded as a very important supportive tool in medicine. It is applied in hospitals, elderly people's homes, schools, alcohol and drug recovery programs, rehabilitation, hospice programs, private practice etc. Although its field of application is very wide medical doctors in general don't possess enough knowledge about it because the subject of Music Medicine is completely missing from the curriculum in medical universities in Hungary in spite of the rich and diversified musical roots of the country. In 2006 a course was initiated for helping the medical students to gain more knowledge about Music Medicine and to dissolve prejudices and misbeliefs about the topic. It was introduced into the medical curriculum as a credit course on the Medical and Health Science Centre of University of Debrecen. The aims of our study were the introduction of the course thematic and quantitative and qualitative analysis of the students' evaluation about the course. The course was focusing both on the theoretical and practical parts of the methods of Music Medicine so the participants had the opportunity for discussing scientific articles about the possibilities of application of Music Medicine in medical practice and also for trying different methods by themselves (e.g., composing, painting and relaxation to music).

The feed-backs of students participating in the study $(n=150)$ were evaluated by a questionnaire consisting of six items and open questions. The evaluation of the course proved to be especially favourable regarding every aspects, such as overall evaluation, met the requirements, participation, group activity, usefulness, and evaluation of the teacher.

The evaluation neither improved nor declined during the years. The reception of the course was favourable from the beginning. It was accompanied by the attention of the students. Nevertheless we could find several significant positive and modest correlations between the items of course evaluation. The individual participation 
was an exemption since it showed significant association only with the general evaluation of the course and with group activity. The reason of it is probably that the large number of participants in groups thus in spite of the common efforts it was impossible to ensure proper time for individual activity for every student. The increased activity of the groups showed positive correlation with all of the evaluation items suggesting that one of the key point of the course's success could be the common activity implemented in a cohesive group. The positive evaluation of the teacher's work forecasted positive opinions in every evaluation item except the individual activity. The reason of it is probably that this course was a new colour on a palette of the medical training since in general student are trained by authoritarian methods and by frontal teaching. Music Medicine course in contrast with the majority of the courses considered the students as partners and involved them into the learning process based on their own experiences.

According to the results of the content analysis based on their anonymous written feed-backs the introduction of the course exerted several positive effects on the efficiency of studies of the medical students. We can conclude that besides transferring useful information regarding the possibilities of applying music in medical practice as a "side-effect" the course improved the group cohesion between students. Since it was the one and only course of the university where the opportunity of Hungarian and foreign students could learn together in the same group it also helped to eliminate prejudices against eachother. The students could learn how to work together in team with people having different cultural backgrounds meanwhile having an insight into a new field of medicine they didn't have any information before. The students also had the opportunity for getting some practical knowledge besides the theoretical ones what proved to be refreshing experience for them. Their self-awareness has improved too thanks to the structure of the course. Some of the participants of the course volunteered in the program of OK (Oncology Concerts) organized for helping the work of the medical team working for the Haematology-Oncology Department of Paediatric Clinic of University of Debrecen. This program was organized on a weekly regular basis.

The major limitation of the study is that we have no data regarding the number of students who rejected the participation in the study. Neither had we collected data neither about nationality, sex and age of the respondents so adjusting for the potential background variables was not possible. Further studies should be implemented for investigating the application of knowledge gained at Music Medicine courses in medical practice by the participants of the course.

As a conclusion it has been ascertained that a Music Medicine course can bring significant advantages in the curriculum of medical students.

\section{REFERENCES}

1. Decker-Voigt, H-H. Schulen der Musiktherapie. Ernst Reinhardt Verlag, München Basel, 2001; pp. 20-32.

2. Kemper, K. J., \& Danhauer, S. C. Music as therapy. Southern Medical Journal, 98(3), 2005;282-288.

3. Zárate, P., \& Diaz, V. Application of Music Therapy in medicine. Revista Médica de Chile, 2001; 129(2), 219-223.

4. Taylor, D.B. Therapeutic Musicians or Musical Physicians: The Future is at Stake. Music Therapy Perspectives, 1988; 5(1), 86-93. Doi: $10.1093 / \mathrm{mtp} / 5.1 .86$

5. Thaut, M. H. The future of music in therapy and medicine. Annals of the New York Academi of Sciences, 1060, 303-308. Doi: 10.1196/ annals. 2005; 1360.023

6. Maranto, C. D. Future trends, issues of accountability, and new models for Music Therapy education and training. Music Therapy Perspectives, 1989; 7(1), 100-102.

7. Ortega, R. A., Andreoli, M. T., \& Chima, R. S. Is there a place for music in medical school? Medical Teacher, 2011: 33(1), 76-77. Doi: 10.3109/0142159X.2010.530705

8. Vargha, A. Új statisztikai módszerekkel új lehetségek: a ROPstat a pszichológiai kutatások szolgálatában. Pszichológia, 2008; 28(1), 81-103. Doi: 10.1556/Pszi.28.2008.1.5

9. Atlas/ti Version 6.2. Computer Software, 2010; Retrieved from http:// atlasti.com/support/downloads. Date of retrieval: 18 October 2014

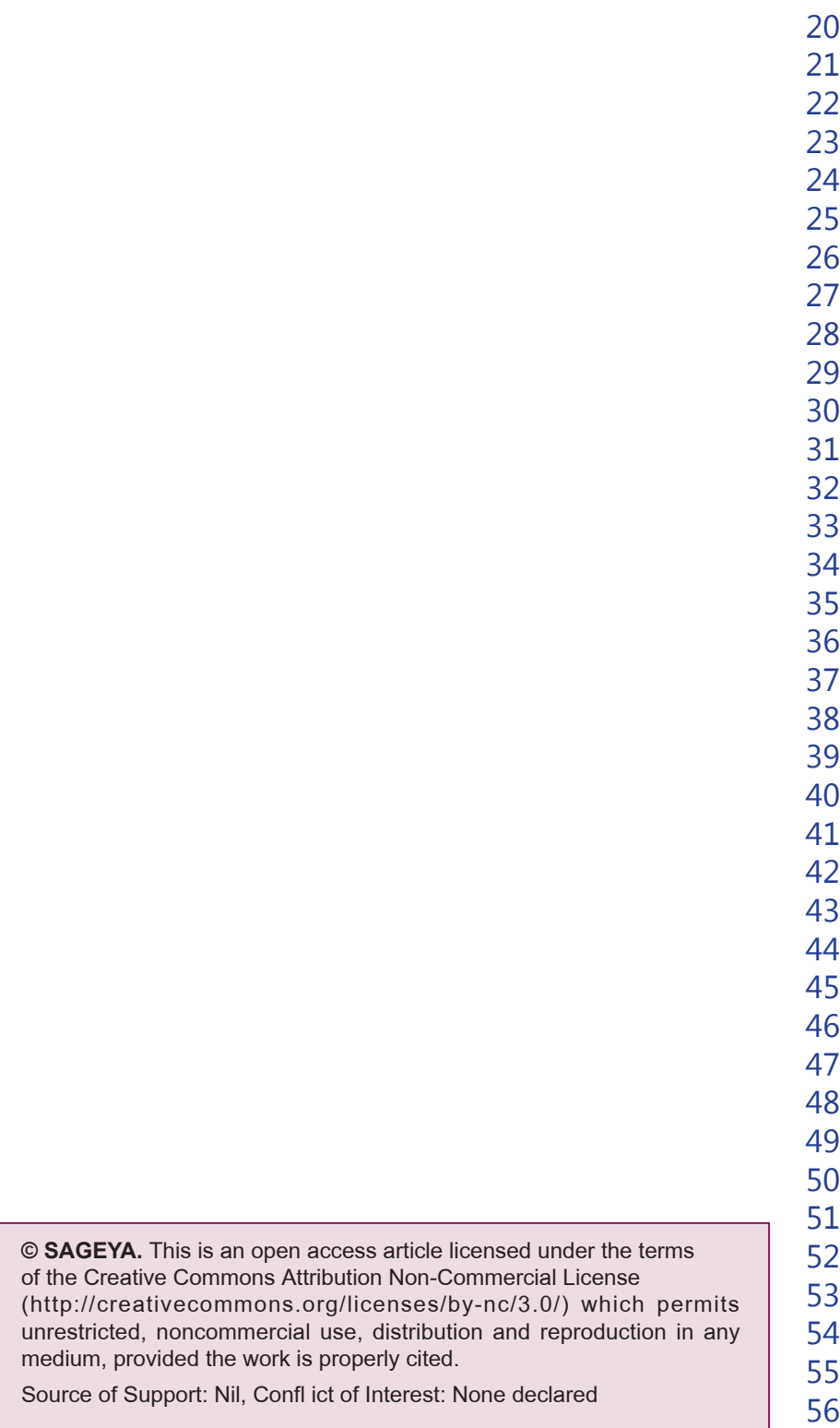


Kollar, et al.: Music med. course for medical students in Hungary

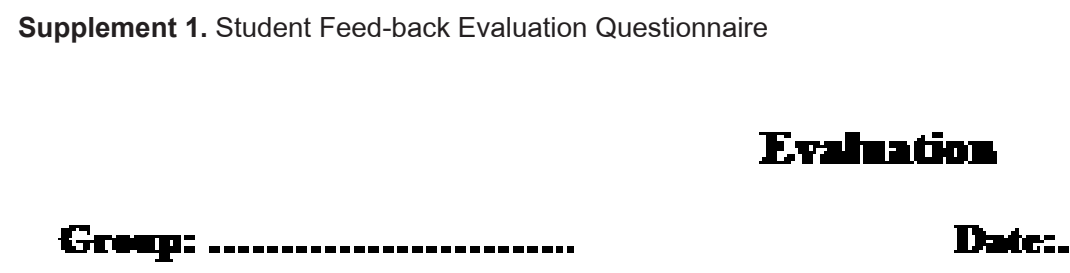

2

3

4

5

Weak

Comments:

Exत्allet

6

Weak

2. How did the exercises net ay epectations?
0
1
2
3
4
5
Exrallext

Comments:

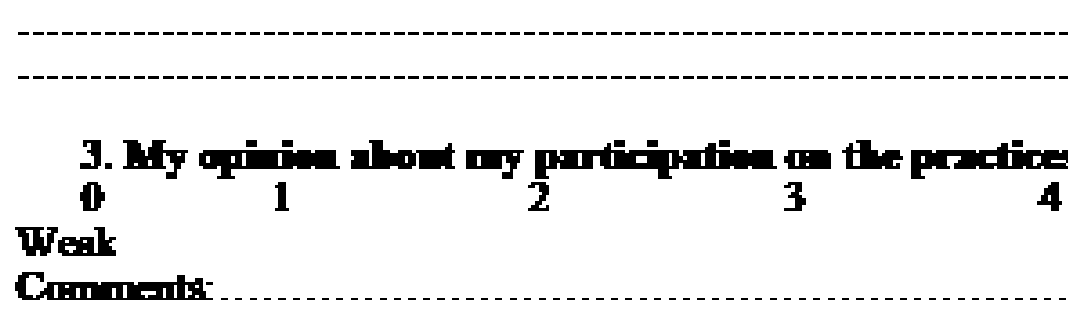

4

Commonts:

$\mathbf{5}$ Expilnt

4. My cilien alout the with af the preap:

Weak

2

Comments:

4

5 Explat

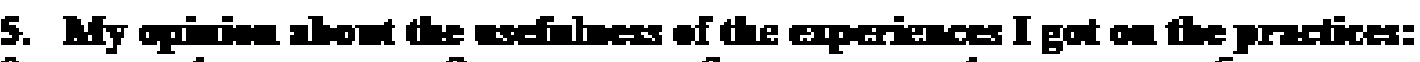

$\begin{array}{lllllll}0 & 1 & 2 & 3 & 4 & 5 & 6\end{array}$

Weak

Exp्ञllet

Comments:

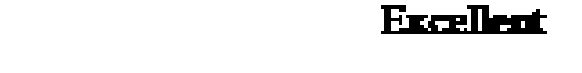

$\mathbf{6}$
$\mathbf{6}$

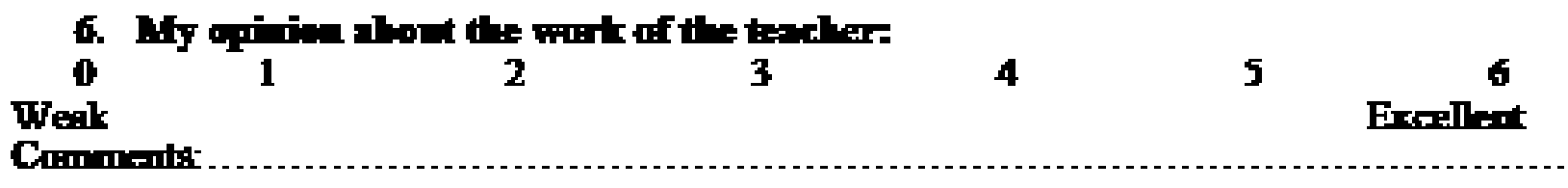

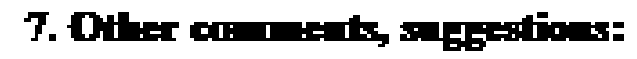

